\title{
ESTUDO DA PERCEPÇÃO DA POPULAÇÃO SOBRE A ARBORIZAÇÃO URBANA, NO MUNICÍPIO DE ALEGRE-ES
}

\author{
Samira Murelli de Souza ${ }^{12}$, Ariana de Lima Cardoso², Aderbal Gomes da Silva ${ }^{2}$
}

\section{RESUMO}

Este estudo teve como objetivo avaliar a percepção ambiental dos moradores sobre a arborização urbana em quatro bairros do município de Alegre, Espírito Santo. A metodologia baseou-se em um questionário, com questões objetivas e do tipo aberta. A aplicação dos questionários foi por amostragem sistemática, a cada cinco residências, participando uma pessoa por residência. O total de entrevistados foi definido a partir do cálculo de $10 \%$, do número de moradias existentes em cada bairro analisado, obtendo-se ao todo, 113 indivíduos participantes. Os resultados demonstraram que a população investigada reconhece a importância da arborização urbana na qualidade de vida e na qualidade ambiental da cidade. As principais funções da arborização viária para a população foram a produção de sombra e redução do calor. A principal desvantagem ressaltada foi a sujeira provocada pelas folhas e frutos nas ruas e calçadas. Por outro lado, formas inadequadas de colaboração foram verificadas, apesar de a maioria da população investigada enfatizar que a responsabilidade pela arborização de Alegre, cabe à Prefeitura Municipal. Como prioridade, verifica-se a necessidade de se criar programas de educação ambiental, visando ressaltar a importância da preservação da arborização, para a manutenção da biodiversidade da cidade de Alegre, ES.

Palavras-chave: Percepção ambiental, árvores, qualidade ambiental.

\section{STUDY OF THE POPULATION'S PERCEPTION ON THE URBAN TREES, IN THE CITY OF}

\section{ALEGRE-ES}

\section{ABSTRACT}

This study aimed to assess the environmental awareness of residents about urban trees in four districts of the municipality of Alegre, Espirito Santo. The methodology was based on a questionnaire with objective questions and open style. The aplication of the questionnaires was by systematic sampling, every five residences, with one person per residence. The total number of respondents was defined by calculating $10 \%$, of the number of houses in each district analyzed, resulting in altogether 113 subjects. The results showed that the investigated population recognizes the importance of urban trees in the quality of life and environmental quality of the city. The main roles of the urban tree planting for the population was the production of shade and heat reduction. The main disadvantage highlighted was dirt caused by the leaves and fruits in the streets and sidewalks. Furthermore, inappropriate forms of collaboration were observed, although the majority of the population investigated emphasize that the responsibility of the urban trees of Alegre, it is the City Hall. As priority, there is need to create environmental education programs in order to emphasize the importance of preservation of the urban tree for the maintenance of biodiversity of the city of Alegre, ES.

Keywords: Environmental perception, trees, environmental quality.

\footnotetext{
${ }^{1}$ recebido em 23.05.2012 e aceito para publicação em 15.06 .2013

${ }^{2}$ Mestres em Ciências Florestais da Universidade Federal do Espírito Santo (UFES) - Centro de Ciências Agrárias. Avenida Governador Lindemberg, 316 - NEDTEC, Jerônimo Monteiro, ES - CEP: 29550-000. E-mails: smurellis@yahoo.com.br; arianaflorestal@yahoo.com.br
} 
Nas últimas décadas a população mundial passou a se concentrar nos centros urbanos, fazendo com que as cidades crescessem na maioria das vezes, de forma muito rápida e desordenada, sem um planejamento adequado de ocupação. Essa situação ocasionou a interferência direta das atividades humanas nos sistemas naturais (RODRIGUES et al., 2010).

Tal urbanização tem como uma de suas marcas principais, a retirada das espécies vegetais para a ocupação dos espaços. Essa alteração do ambiente, antes natural, provoca vários problemas que interferem sobremaneira na qualidade de vida de quem vive na cidade (PIVETTA e SILVA FILHO, 2002).

Segundo Zinkoski e Loboda (2005), dentre os problemas cruciais do desenvolvimento nada harmonioso entre a cidade e a natureza, destacamse: a substituição de valores naturais por ruídos, concreto, máquinas, edificações, poluição, intensificação de enchentes, alteração microclimática, ilhas de calor, etc.

Para evitar e ou amenizar os problemas originados pela urbanização, é necessário incluir a vegetação como um fator indispensável no planejamento das cidades, em decorrência dos vários benefícios que proporciona ao meio urbano. As diferenças entre as regiões arborizadas e aquelas desprovidas de arborização são facilmente percebidas, sendo os locais arborizados muito mais agradáveis aos sentidos humanos.

Neste sentido, Stringheta (2005) cita que o ato de arborizar cidades surgiu da necessidade de se manter o vínculo com a natureza, pois a arborização urbana humaniza os espaços das cidades, permitindo que se desfrute a denominada “qualidade de vida urbana”.
No entanto, apesar da reconhecida necessidade da arborização viária, por muitas vezes, foi considerada "um problema” de menor importância, no planejamento urbano das administrações públicas. Somente nas últimas décadas é que se vem integrando no instrumental legislativo das cidades brasileiras (LOBODA et al., 2005).

Contudo, ainda é comum o fracasso dos plantios ou da manutenção dessas áreas. Isso se deve, principalmente, à ausência de conscientização sobre a importância da mesma e à falta da participação comunitária, fazendo-se necessário, para um eficiente planejamento e manutenção da arborização, considerar a percepção da população. Segundo Oliveira (2005) os estudos que enfoquem a percepção da população em relação ao meio ambiente, devem servir como um instrumento para a administração municipal utilizar no planejamento e gestão de áreas verdes, atendendo a população por meio de políticas públicas, estabelecendo programas de educação ambiental e incentivando estudos acadêmicos na área. Além de possibilitar a participação da comunidade no desenvolvimento e planejamento regional, criando um vínculo entre os habitantes e a questão ambiental.

Neste contexto, o estudo da percepção ambiental da população, possibilita obter informações de grande importância, porque emergem da vivência em relação a tudo que faz parte do cotidiano. Em razão disso, esses estudos devem ser levados em consideração para a gestão sustentável da arborização urbana, para refletir as aspirações de quem reside no local, e quem sente diretamente, o impacto da qualidade ambiental (MACHADO, 1993).

Em vista do exposto, objetivou-se com este trabalho, analisar a percepção ambiental dos 
moradores de diferentes bairros, do município de Alegre-ES, com relação à arborização urbana, identificando o nível de satisfação da população conforme a variação do nível de arborização.

\section{MATERIAL E MÉTODOS}

\section{Descrição da área de estudo}

O estudo foi realizado no município de Alegre, região Sul do Estado do Espírito Santo (Figura 1). Localizado entre as coordenadas geográficas 2045'49" de Latitude Sul e 41³1'57" de Longitude
Oeste, o município abrange uma área de $773 \mathrm{~km}^{2} \mathrm{e}$ uma população de 30.768 habitantes, segundo dados do IBGE (2010).

FIGURA 1. Localização da área de estudo, Alegre-ES.

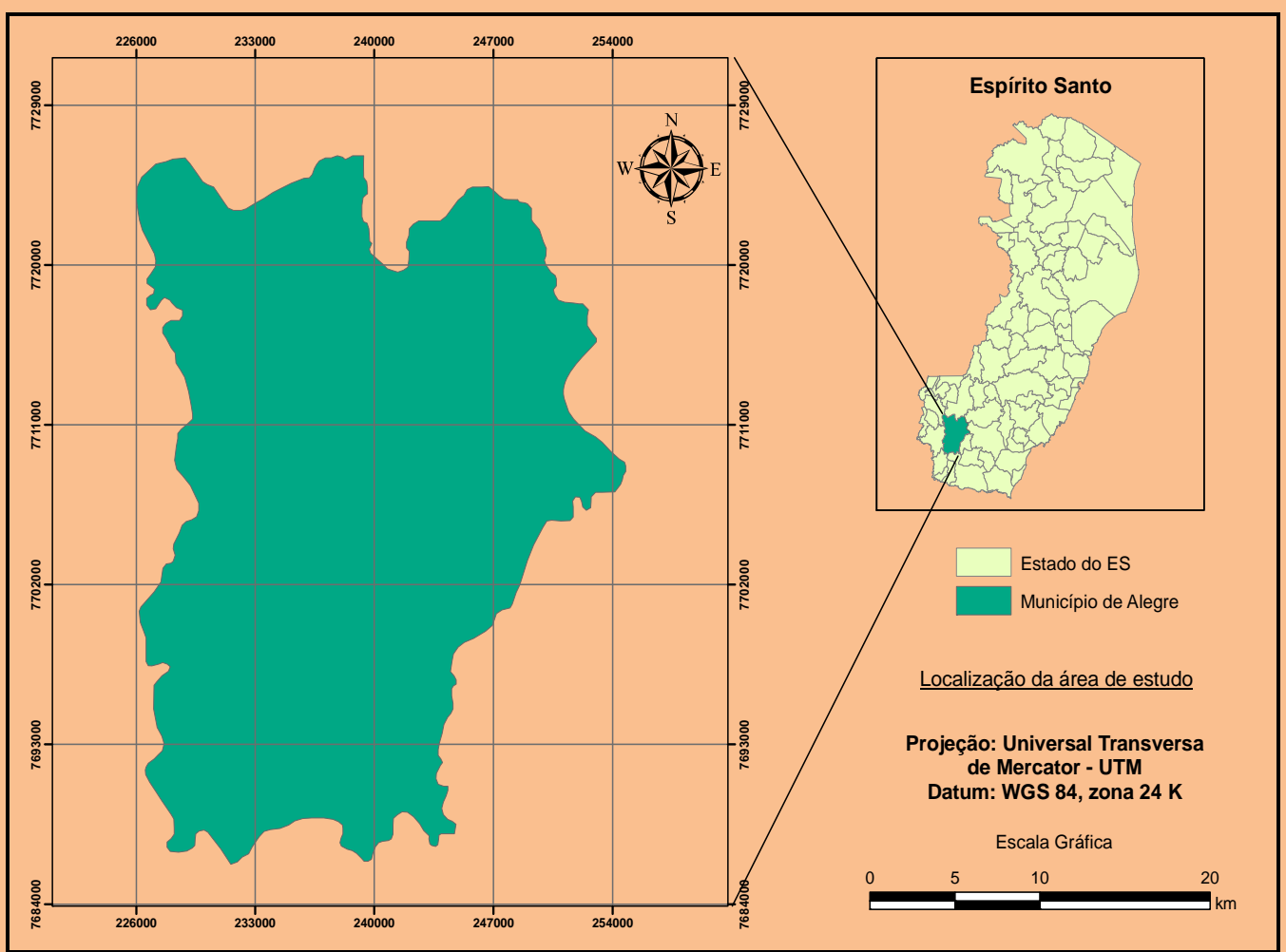

O clima é, segundo a classificação de Köppen, do tipo Cwa, com estação seca no inverno e verão quente e chuvoso - com temperatura média anual de $22,2^{\circ} \mathrm{C}$, variando de $17^{\circ}$ e $29^{\circ} \mathrm{C}$. Com um relevo bastante acidentado e elevado, o município apresenta altitude de $100 \mathrm{~m}$ a mínima e $1.326 \mathrm{~m}$ a máxima, sendo $250 \mathrm{~m}$ na sede (PREFEITURA MUNICIPAL DE ALEGRE, 2011a). 


\section{Metodologia específica}

A metodologia empregada para a realização do presente estudo fundamentou-se em um questionário, contendo dez questões, dentre elas perguntas objetivas e do tipo aberta (de opinião própria), baseado no questionário elaborado por Roppa et al., (2007). O questionário foi aplicado aos moradores de quatro bairros que compõem o perímetro urbano de Alegre, sendo eles: Centro, Vila do Sul, Nova Alegre e Guararema. Foram definidos esses bairros, por suas localizações contemplarem toda a extensão do perímetro urbano da cidade.

Os questionários foram aplicados em residências (excluindo-se os comércios), escolhidas por amostragem sistemática, num intervalo de um questionário a cada cinco residências. O número de casas participantes foi definido, a partir do cálculo de $10 \%$, do total de moradias existentes em cada bairro analisado, sendo entrevistado somente um morador por residência. O critério de escolha dos indivíduos convidados a participar da pesquisa foi, essencialmente, terem idade mínima de 15 anos. Foi dispensável que os entrevistados fossem moradores das áreas avaliadas, visto que nos momentos das pesquisas alguns proprietários das casas encontravam-se ausentes. Os participantes foram então, identificados e classificados por sexo, faixa etária e nível de escolaridade, para posterior preenchimento das questões.

No estudo, foi abordado, o nível de satisfação dos moradores na configuração e distribuição das árvores em suas ruas; vantagens e desvantagens apresentadas pela arborização; forma de colaboração por parte do entrevistado e, perspectivas e sugestões para a melhoria da situação do verde urbano da área de estudo, dentre outros.

A pesquisa foi realizada entre os meses de Junho e Julho de 2009. Os dados obtidos foram inseridos em um banco de dados construído no software Microsoft Excel 7.0 e, em seguida processados para a análise dos resultados.

\section{RESULTADOS E DISCUSSÃO}

De acordo com pesquisas à unidade do IBGE da cidade de Alegre, encontrou-se um total de 374 residências no bairro Centro (37 entrevistados); 343 na Vila do Sul (34 entrevistados); 172 em Nova Alegre (17 entrevistados) e, 251 na Guararema (25 entrevistados). Desta forma, ao todo, 113 pessoas participaram da pesquisa.

No que tange ao perfil da população participante, a maioria dos entrevistados, nos quatro bairros de Alegre, era do sexo feminino, destacando-se o bairro Guararema, com $88 \%$ de mulheres respondendo ao questionário, contra apenas 12\% de homens. A faixa etária que predominou entre os indivíduos de cada bairro, foi a superior a 50 anos, enquanto a minoria correspondeu àqueles com idade entre 15 e 20 anos. Além disso, observou-se que o maior número de participantes em cada bairro avaliado, possuía apenas o ensino fundamental completo (Tabela 1). 
TABELA 1. Perfil dos entrevistados nas quatro áreas avaliadas do município de Alegre, Estado do Espírito

Santo.

\begin{tabular}{lcccc}
\hline \multicolumn{1}{c}{ Variáveis } & Centro (\%) & Guararema (\%) & Nova Alegre (\%) & Vila do Sul (\%) \\
\hline Gênero & & & & \\
Masculino & 27 & 12 & 24 & 32 \\
Feminino & 73 & 88 & 76 & 68 \\
\hline Faixa etária & & & & \\
Entre 15 e 20 anos & 8 & 4 & 6 & 18 \\
Entre 21 e 30 anos & 16 & 24 & 29 & 12 \\
Entre 31 e 50 anos & 32 & 24 & 29 & 50 \\
Mais que 50 anos & 43 & 48 & 35 & \\
\hline Escolaridade & & & & 44 \\
EFC* & 43 & 68 & 12 & 24 \\
EMC* & 30 & 16 & 35 & 32 \\
ESC* & 27 & 16 & 12 & \\
\hline
\end{tabular}

*Legenda: EFC: ensino fundamental completo; EMC: ensino médio completo; ESC: ensino superior completo.

Os resultados diferiram daqueles encontrados por Malavasi e Malavasi (2001), em um estudo realizado na cidade de Mal. Cândido Rondon, Paraná, em que, 59\% dos participantes eram do sexo masculino e $41 \%$ do sexo feminino. Já no nível de escolaridade, o autor destacou que $11,2 \%$ possuíam o ensino fundamental completo, 26,6\% possuíam o ensino médio completo, enquanto 7,7\% haviam completado o ensino superior.

O fato da maior parte dos entrevistados possuir apenas o ensino fundamental se deu por dois principais motivos. Primeiro, pela maioria ser constituída por idosos, que descreveram não ter tido oportunidades de continuar os estudos, em suas juventudes. O outro motivo foi que pela ausência dos proprietários de algumas residências durante as entrevistas, as responsáveis nestes casos, eram, geralmente, empregadas domésticas sem muito estudo, e que já trabalhavam no local há alguns meses, o que as possibilitaram de responder sobre a arborização das ruas em questão.

Por meio da metodologia aplicada no presente trabalho, verificou-se que a população representativa do município de Alegre, de maneira geral, possui uma percepção favorável com relação à arborização urbana, pois, quando questionados se gostavam ou não de ruas arborizadas, predominouse a resposta positiva.

Nos bairros, Nova Alegre e Vila do Sul, todos os participantes (100\%) responderam que sim. Já nos bairros, Centro e Guararema, 92\% dos entrevistados de cada bairro, disseram gostar da presença das árvores nas ruas do município, estando uma pequena parcela contra. Alguns participantes não souberam justificar a importância da árvore mesmo sendo a favor dela, mas a maioria disse gostar da arborização, demonstrando compreender o significado positivo da árvore na qualidade de vida, associando paisagem com aproximação da natureza, diminuição de incidência solar com sombreamento, redução na concentração de dióxido de carbono com redução da poluição e a relação da arborização com as mudanças climáticas, demonstrando suas percepções ambientais.

Os desfavoráveis à arborização justificaram, sobretudo, que as árvores trazem sujeira à cidade, relatando durante a entrevista que as folhas “entopem” bueiros.

Estes resultados equiparam-se aos registrados por Malavasi e Malavasi (2001), em Mal. Cândido

Samira Murelli de Souza et al. 
Rondon, Paraná, que apontaram 92\% dos entrevistados como favoráveis à arborização, relacionando-a a melhoria da qualidade do ar, a aspectos estéticos, ao sombreamento e a qualidade de vida. Quanto às desvantagens, os autores relatam que os $8 \%$ referem-se a inconvenientes como sujeira. Quadros e Frei (2009) também encontraram resultado semelhante, em que prevaleceram as opiniões favoráveis à arborização urbana, com 97\% dos entrevistados na cidade de Assis, SP.

Em relação à questão da altura das árvores, foram definidas três classes de tamanho, sendo elas: árvores baixas ou de pequeno porte $(<5 \mathrm{~m})$, árvores médias ou de médio porte (entre 5 e $8 \mathrm{~m}$ ) e árvores altas ou de grande porte (acima de $8 \mathrm{~m}$ ), como pode ser observado na Figura 2.

FIGURA 2. Percentual de entrevistados em função da preferência da altura das árvores, nos quatro bairros avaliados do município de Alegre, ES.

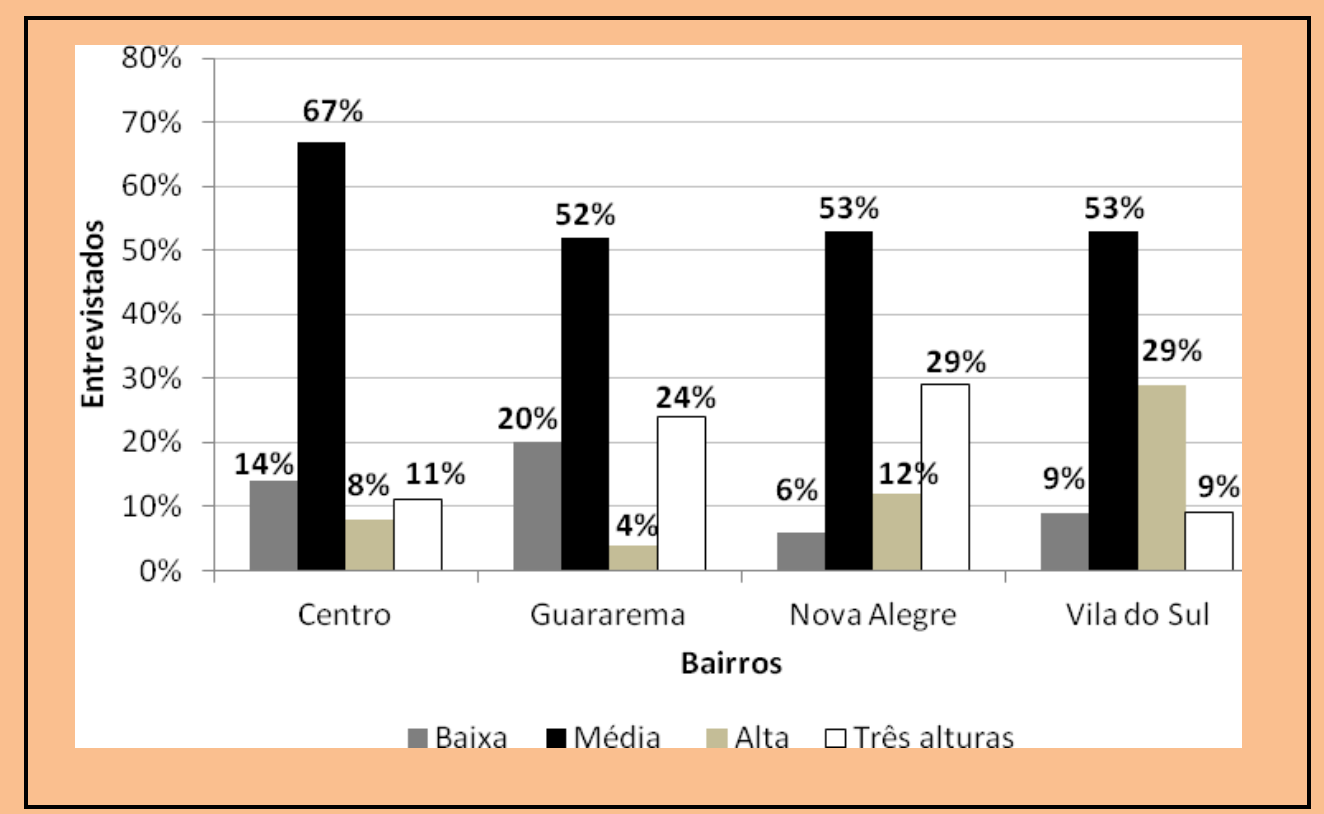

A maioria dos entrevistados optou por árvores de médio porte, justificando o conflito das mesmas com a rede elétrica e edificações. Esse problema, quando ocorre, é devido a uma falta de planejamento adequado. Segundo Teixeira (1999), para uma maior, ou melhor, qualidade da arborização de ruas, a composição percentual das espécies utilizadas e a compatibilização entre o porte das árvores e o espaço físico disponível para o plantio, nem sempre são adequadamente considerados.

Nota-se também que, no bairro Vila do Sul, a segunda maior preferência (29\%) é por árvores altas. No bairro Nova Alegre, o mesmo percentual de entrevistados (29\%) já prefere árvores com as três alturas, ou seja, uma arborização diversificada. No bairro Guararema, 24\% dos entrevistados também disseram preferir a presença de árvores com as três alturas em suas ruas, enquanto no bairro Centro, apenas $14 \%$ optaram por árvores de baixo porte.

Essa situação assemelha-se ao resultado encontrado no estudo de Oliveira (2005), onde a maioria das pessoas entrevistadas na Avenida Afonso Pena, Campo Grande, disse preferir árvores de porte médio. 
As opiniões dos moradores representam de certa forma, as condições encontradas por eles nas ruas de seus bairros. Ao conviverem e acostumarem com árvores baixas, médias ou altas, dá-se preferência a essas alturas. Essas respostas podem sugerir também que, mesmo inconscientemente, as pessoas relacionam a altura das árvores com as vantagens proporcionadas por elas, pois os benefícios da arborização mais citados foram sombra, clima e paisagem, podendo, todos esses, serem encontrados em árvores de altura média.

$\mathrm{Na}$ sequência, foi perguntado sobre o sombreamento das ruas, proporcionado pelas árvores. Na Figura 3, podem-se verificar os resultados desse questionamento, de acordo com cada bairro avaliado.

FIGURA 3. Percentual de entrevistados nos bairros do município de Alegre-ES quanto ao sombreamento proporcionado pela arborização de suas ruas.

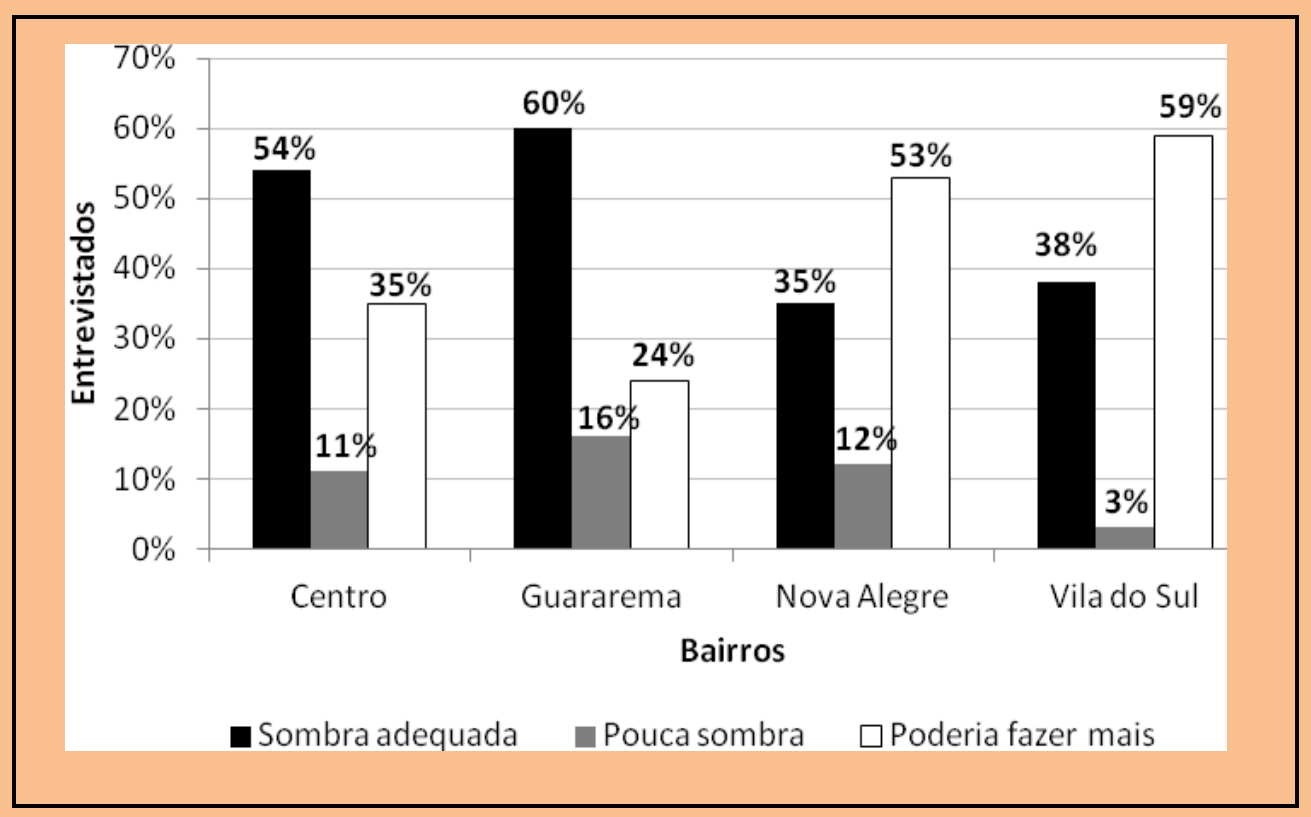

Nos bairros Centro e Guararema, a maior parte, representada respectivamente por $54 \%$ e $60 \%$, disseram que a arborização de suas ruas promove sombreamento adequado. Enquanto isso, nos bairros Nova Alegre (53\%) e Vila do Sul (59\%), prevaleceram os que responderam que a arborização poderia promover mais sombra em suas respectivas ruas.

Vale ressaltar que a preocupação da população de Alegre, em geral, em relação ao sombreamento oferecido pelas árvores, se dá pela amenização microclimática proveniente da redução da temperatura e aumento da umidade relativa do ar, principalmente no verão, visto que Alegre é uma cidade com temperaturas elevadas, durante quase todo ano, o que traz grande desconforto térmico à população.

Quando o assunto foi a ventilação das ruas, proporcionada pela arborização, obteve-se unanimidade na opinião de que os bairros estudados possuem ventilação adequada. No Centro, 89\% dos entrevistados alegaram que a ventilação é satisfatória. Na Guararema, 92\% concordaram com a afirmativa. No bairro Nova Alegre, todos os entrevistados responderam positivamente, e na Vila do Sul $82 \%$ também disseram que sim. 
Dessa parcela positiva, a maioria associou a ventilação ao fato de as árvores não atrapalharem a circulação do vento em seus bairros. Quanto aos discordantes, a opinião foi de que a arborização impedia o fluxo de ar pelas ruas dos bairros, por meio de suas copas.
No questionamento seguinte, buscou-se investigar como os entrevistados classificam a rua onde residem e/ou frequentam. Na Figura 4 apresenta-se a percepção dos participantes em relação ao grau de arborização das áreas estudadas.

FIGURA 4. Grau de arborização das ruas conforme a percepção dos entrevistados, nos diferentes bairros do município de Alegre, Espírito Santo.

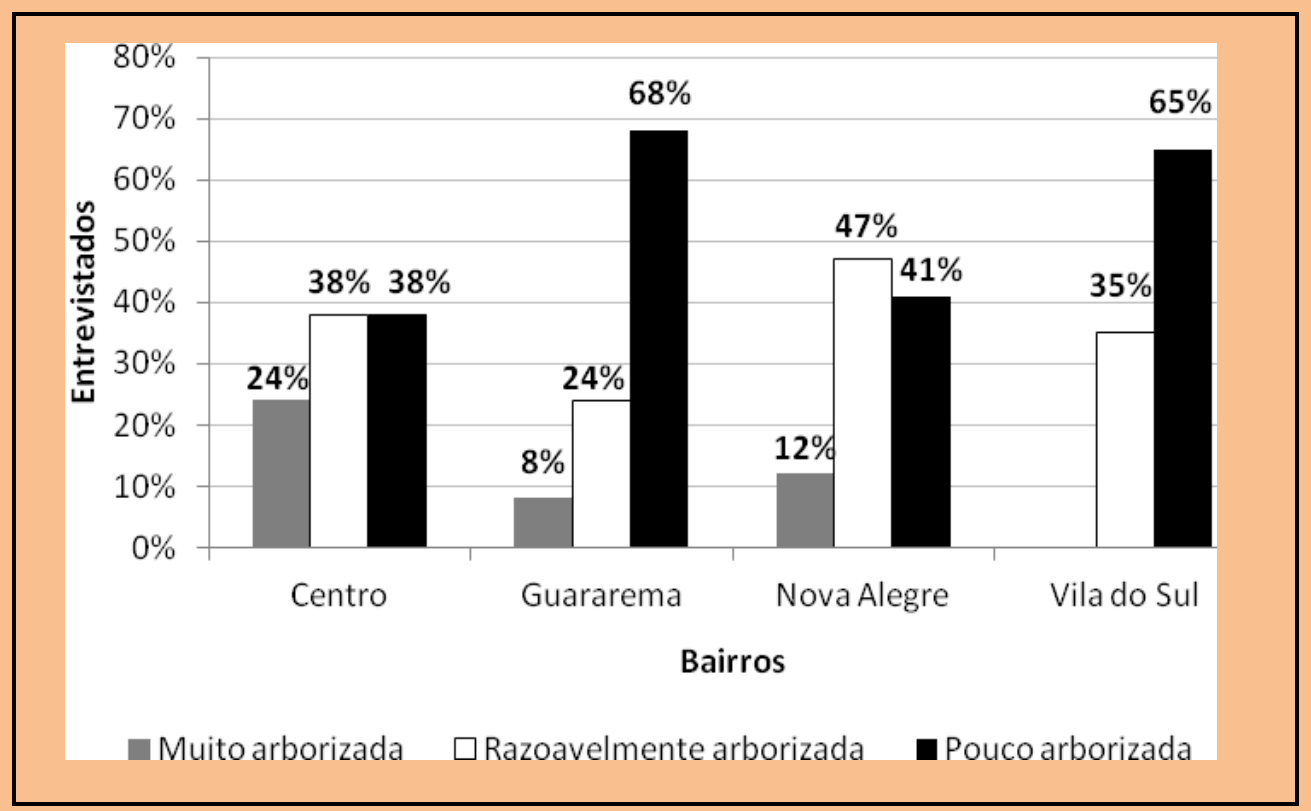

Conforme os dados contidos na Figura acima, verificou-se em todas as áreas selecionadas uma variação nas respostas dos entrevistados, ainda que o município de Alegre seja uma região, em geral, com pouca presença de árvores nas ruas.

Analisando o bairro Centro, observou-se que houve o mesmo percentual de respostas para ruas razoavelmente (38\%) e pouco arborizadas (38\%), enquanto $24 \%$ classificaram suas ruas como muito arborizadas.

Em Nova Alegre, os percentuais das classificações 'razoavelmente arborizadas' e 'pouco arborizadas' permaneceram próximos, num total de $47 \%$ e $41 \%$, respectivamente, contra $12 \%$ de opiniões para ruas muito arborizadas.
A ausência de arborização nas ruas foi mais evidenciada nos bairros Guararema (68\%) e na Vila do Sul (65\%). Ainda nesse último, 35\% dos participantes classificaram suas ruas como razoavelmente arborizadas. Para as ruas 'pouco arborizadas', os entrevistados alegaram a culpa, principalmente à falta de planejamento da urbanização do local, com falta de padronização no calçamento, impedindo a implantação adequada de áreas livres para as árvores.

Segundo Roppa et al. (2007), por serem informações obtidas a partir da percepção dos entrevistados, entende-se que este tipo de avaliação tende a ser muito subjetiva, dependendo em grande parte da maior ou menor vivência da pessoa no 
local, pelo fato de que muitos tendem a avaliar a arborização do bairro apenas levando em conta a sua rua, ou mesmo as árvores que se encontram em frente a sua casa.
Na Figura 5, podem-se visualizar as respostas da população quando questionada sobre as principais vantagens das árvores em suas ruas.

FIGURA 5. Vantagens da arborização urbana atribuídas pelos entrevistados, nos quatro bairros avaliados do município de Alegre, ES.

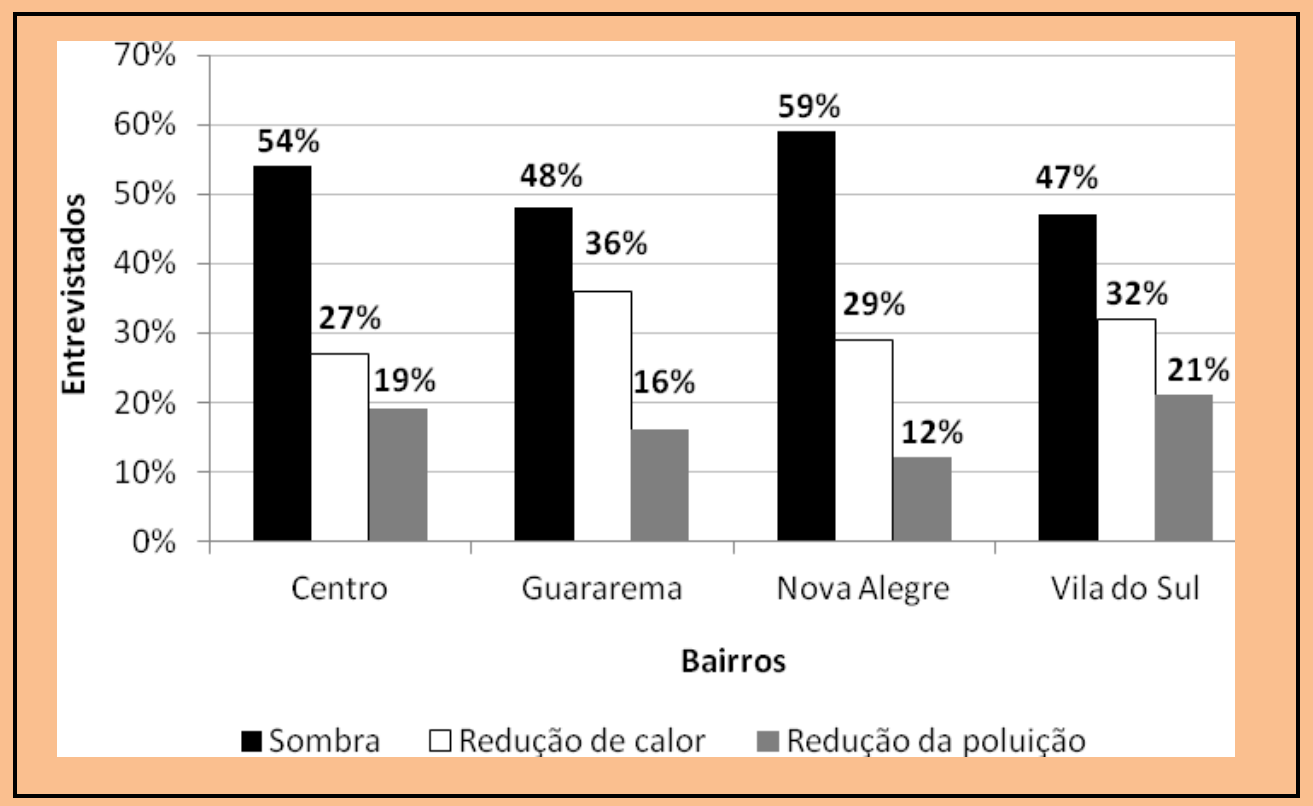

Nota-se que no bairro Centro, 54\% citaram o sombreamento como o principal benefício e $27 \%$ a redução do calor. Na Guararema, 48\% e 36\% também responderam o sombreamento e a redução do calor, respectivamente. No bairro Nova Alegre, foi obtido o maior percentual para o benefício sombreamento (59\%), enquanto $29 \%$ optaram pela redução do calor. Por último, na Vila do Sul, 47\% escolheram o sombreamento como a principal característica positiva das árvores e 32\% apontaram a redução do calor.

Essas vantagens se justificam pela ocorrência de temperaturas elevadas durante o verão, as quais impulsionam a população a buscar diferentes meios que lhe proporcionem maior conforto térmico. Segundo Santos e Teixeira (2001), embora a vegetação não possa controlar totalmente as condições de desconforto, ela pode, eficientemente, abrandar a sua intensidade.

De maneira geral, o benefício ligado à redução da poluição teve um nível de percepção menor, variando de 12 a $21 \%$ entre os quatro bairros em estudo. Os quesitos ligados à poluição foram interpretados pelos entrevistados, como sendo poluição atmosférica, sonora ou visual. Como a cidade de Alegre pode ser considerada um local com pouca arborização entende-se o motivo, pelo qual, essa vantagem se torna pouco percebida pelos moradores.

Resultados semelhantes quanto às vantagens proporcionadas pela arborização urbana foram encontrados nos estudos de Malavasi e Malavasi (2001) no Paraná, Roppa et al. (2007) em Santa Maria-RS, Brun et al. (2009) também em Santa 
Maria-RS, Ribeiro (2009) em Uberlândia-MG e Rodrigues et al. (2010) em Goiás. Em todos esses estudos, o sombreamento e a redução do calor foram as principais vantagens das árvores do perímetro urbano, apontadas pelos entrevistados.
Com base na Figura 6, observa-se desta vez, a percepção dos entrevistados quanto às desvantagens da arborização urbana.

FIGURA 6. Desvantagens da arborização urbana atribuídas pelos entrevistados, nos quatro bairros avaliados do município de Alegre, ES.

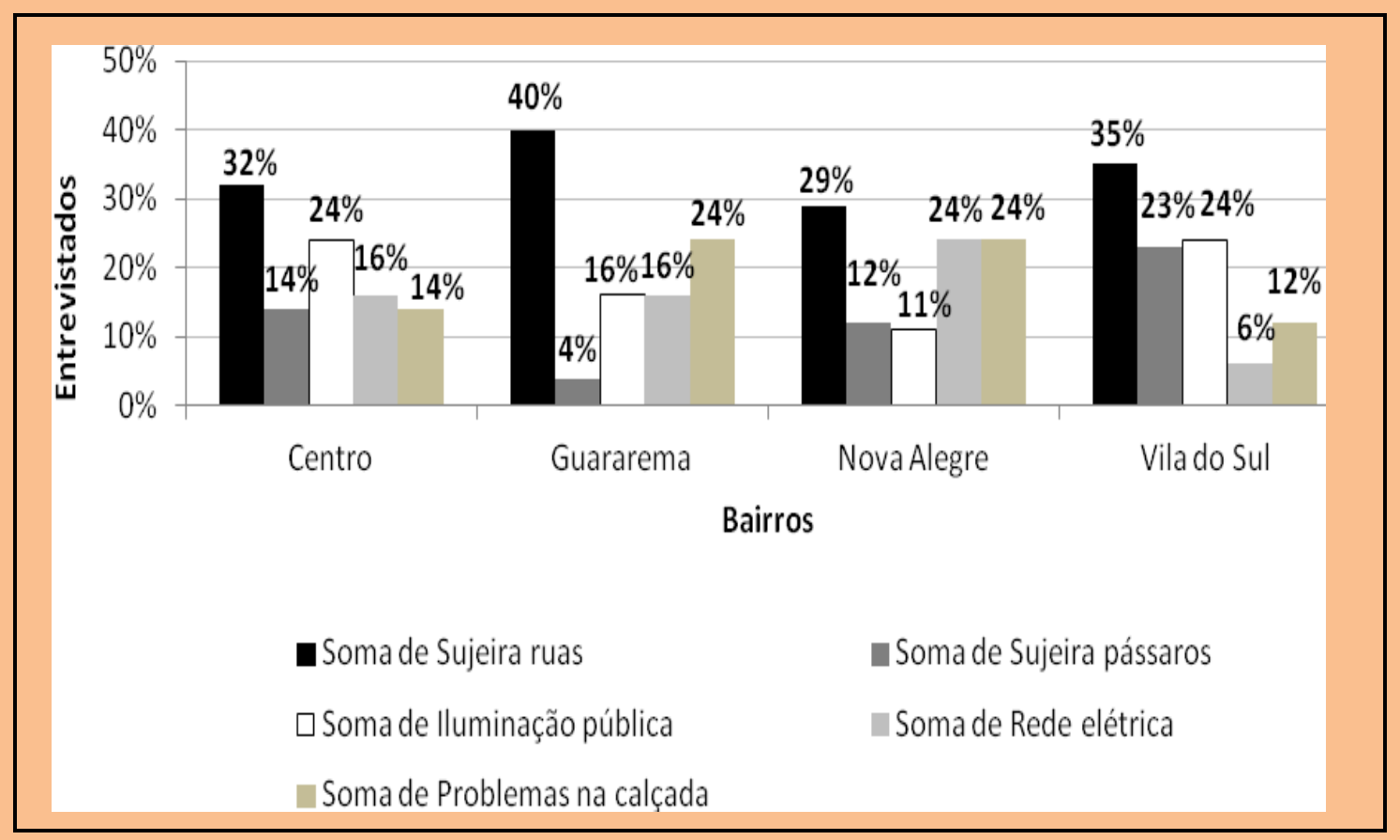

Como principal desvantagem percebida pelos entrevistados, a sujeiras das ruas e calçadas foi predominante nos quatro locais.

Com relação aos valores percentuais, o bairro Guararema apresentou o maior percentual (40\%) das opiniões para sujeiras das ruas, seguido do bairro Vila do Sul (35\%), Centro (32\%) e Nova Alegre (29\%). Para esses participantes, a sujeira provocada pela queda de folhas, frutos e galhos, é o fator de maior incômodo da presença de árvores em suas ruas.

As demais desvantagens mencionadas pelos participantes da pesquisa foram as sujeiras provocadas por pássaros atraídos pela presença das árvores, redução da iluminação pública em locais com maior concentração de arborização, conflitos com rede elétrica e telefônica (fiação aérea) e problemas de danos e incompatibilidade do sistema radicular com o calçamento.

Grande parte desses problemas decorre da falta de orientação técnica no momento de seleção da espécie a ser plantada na via pública, visto que muitas das espécies presentes em Alegre foram introduzidas pelos próprios moradores, decididos a plantar árvores em frente suas casas. Por sua vez, por não possuírem informações técnicas necessárias sobre arborização urbana, os moradores acabam não considerando o fato de que as mudas de médio a grande porte irão crescer, e assim as copas das 
árvores causarão danos às fiações e os sistemas radiculares causarão danos às calçadas.

Para Santos e Teixeira (2001), a árvore como elemento estruturador de espaços, responsável por qualidades estético-visuais e de bem-estar, passa a construir um problema urbano, quando decorrente de planos ineficientes, inexistência de políticas no setor, improvisos e falta de conscientização.
No Centro de Alegre, a redução da iluminação pública ficou como o segundo principal problema da arborização das ruas neste bairro (24\%). Esse resultado foi mais ocasionado pela presença de uma praça, conhecida como Praça da Prefeitura, composta por vegetação abundante e fechada, como pode ser visto na Figura 7.

FIGURA 7. Praça da Prefeitura, localizada no Bairro Centro, município de Alegre, ES.

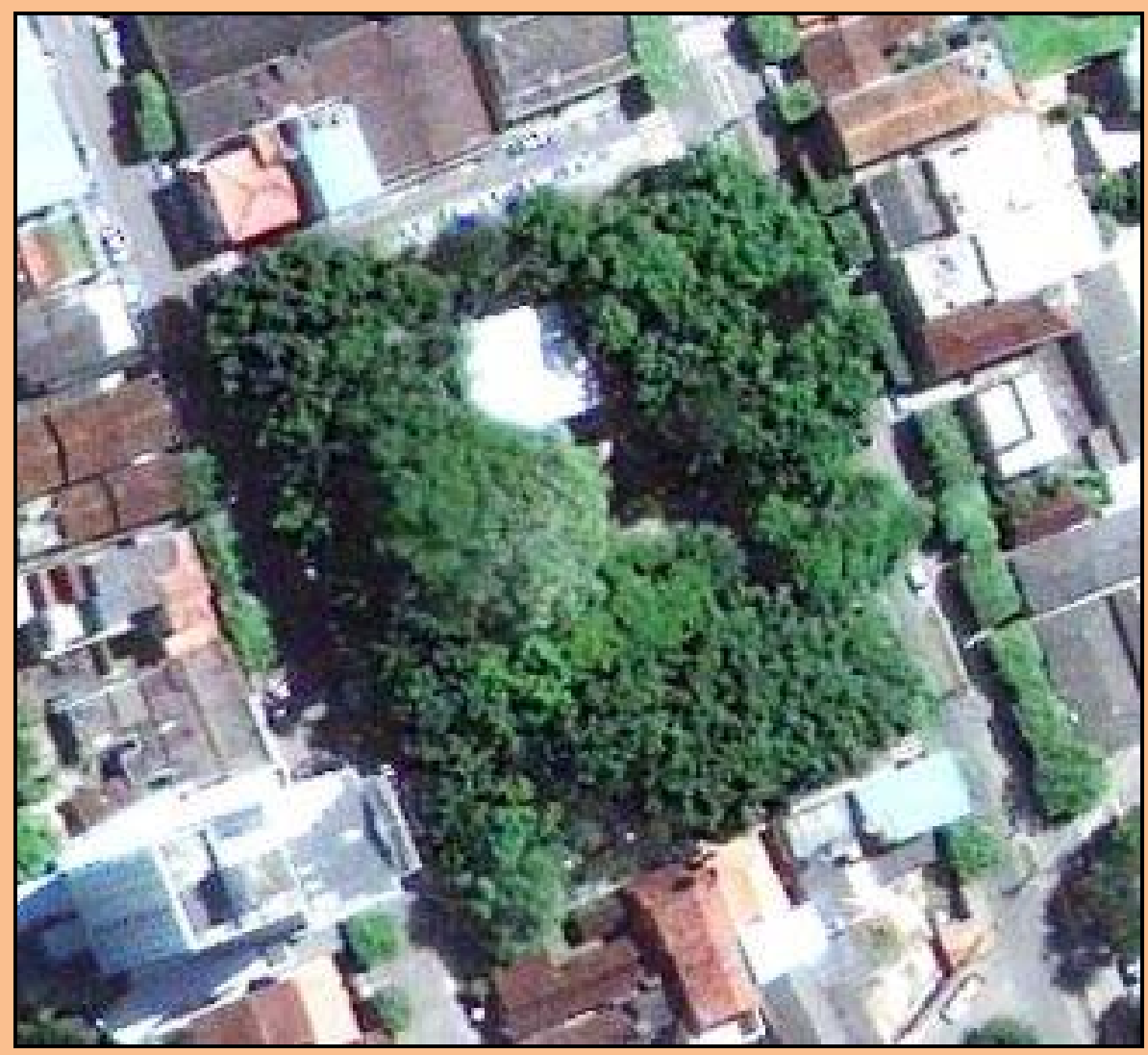

Ao entardecer, a vegetação da praça diminui muito a luminosidade da rua, gerando preocupações com a segurança no local para a vizinhança e transeuntes. Além disso, o conjunto denso de árvores, afeta diretamente a população ao redor, uma vez que as copas e galhos avançam sobre os quintais das casas mais próximas.
Quando abordados sobre a Instituição responsável para o encaminhamento de questões referentes à arborização (plantio, podas ou cortes), grande parte dos entrevistados deu sua opinião, justificando não ter certeza da resposta correta. Os resultados encontram-se na Figura 8. 
FIGURA 8. Órgãos públicos e privados utilizados pelos entrevistados para o encaminhamento de questões referentes à arborização urbana, nos bairros avaliados do município de Alegre, ES.

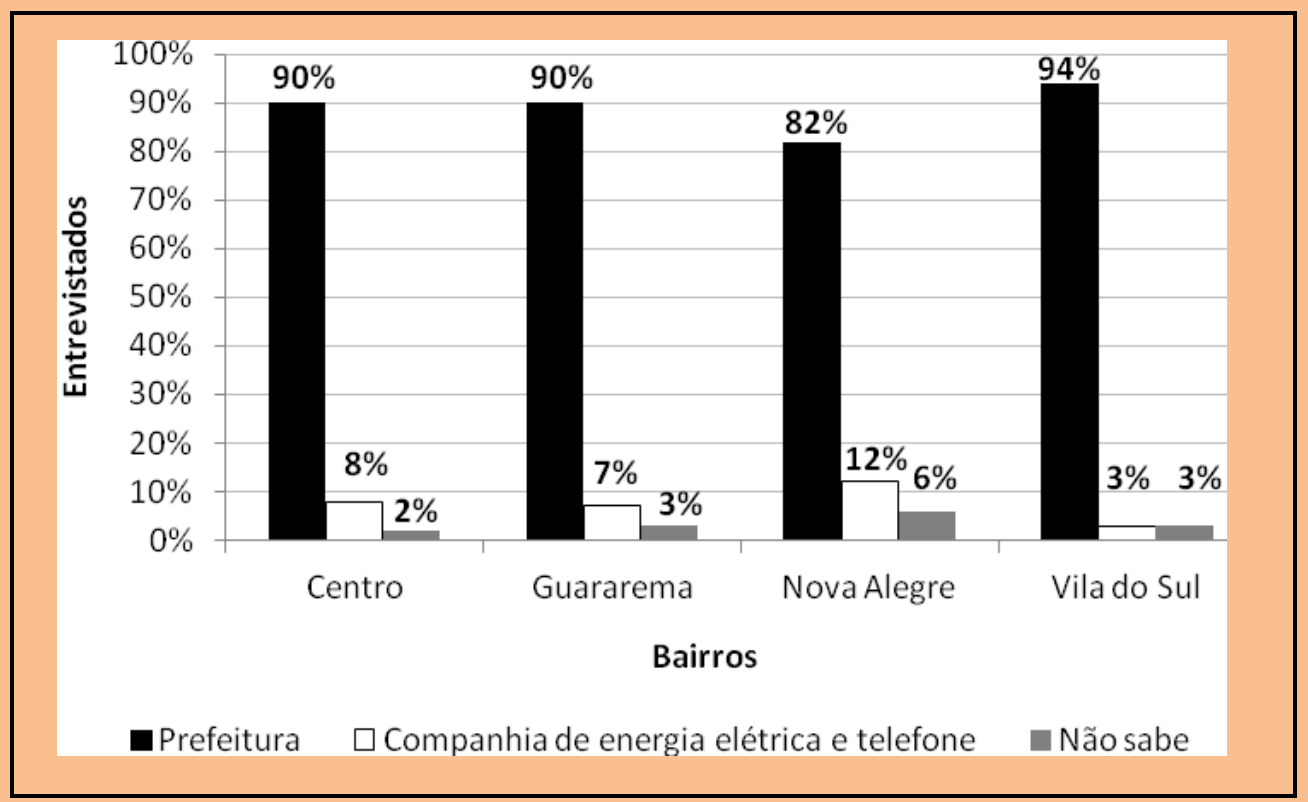

De acordo com os participantes, a Instituição mais procurada, por unanimidade, é a Prefeitura Municipal de Alegre. Nos bairros Centro, Guararema, Nova Alegre e Vila do Sul, os percentuais para essa resposta foram de $90 \%$, 90\%, $82 \%$ e 94\%, respectivamente.

O setor responsável por receber as dúvidas, sugestões ou reclamações referentes à arborização urbana, é a Secretaria Municipal de Agricultura e Meio Ambiente (PREFEITURA MUNICIPAL DE ALEGRE, 2011b). Ainda assim, muitos cortes e podas são realizados pelos moradores de Alegre, devido, principalmente, ao desconhecimento da responsabilidade municipal.

Conforme Silva et al. (2007), o desconhecimento dos moradores sobre o responsável pela arborização na cidade é um problema que se reflete na paisagem. A função do responsável repercute nos moradores de duas maneiras: a instrução do manejo adequado e a aplicação da sanção aos infratores. Neste sentido, as pessoas plantam sem conhecimento do tipo de espécie mais adequada e, ainda mais grave, supõem que podem suprimir a árvore quando quiserem.

Dado o desconhecimento da responsabilidade do órgão municipal, os moradores também tendem a procurar as Companhias de energia elétrica e telefonia, para sanar questões da arborização urbana. Nos bairros em estudo, essas Companhias privadas representaram a segunda resposta mais mencionada pelos entrevistados, cujos percentuais foram de $8 \%$ no Centro de Alegre, 7\% no bairro Guararema, $12 \%$ em Nova Alegre e 3\% na Vila do Sul.

Outra questão tratada na presente pesquisa, diz respeito à investigação sobre se os entrevistados colaboram com a arborização de suas ruas (Tabela 2) e, se sim, de que forma fazem isso. 
TABELA 2. Percentual dos entrevistados que colaboram com a arborização de suas ruas, nos bairros avaliados do município de Alegre, ES.

\begin{tabular}{lcc}
\hline Bairros & SIM (\%) & NÃO (\%) \\
\hline Centro & 32 & 68 \\
Guararema & 44 & 56 \\
Nova Alegre & 88 & 12 \\
Vila do Sul & 47 & 53 \\
\hline
\end{tabular}

Nota-se que nos bairros Centro, Guararema e Vila do Sul, a maioria alegou não colaborar com a arborização de suas ruas. De forma diferente, no bairro Nova Alegre prevaleceram os indivíduos que colaboram ou já colaboraram de alguma forma, com a arborização viária. As principais formas de colaboração apontadas pelos entrevistados apresentam-se na Figura 9.

FIGURA 9. Formas de colaboração na arborização urbana, por parte da população entrevistada nos quatro bairros avaliados do município de Alegre, ES.

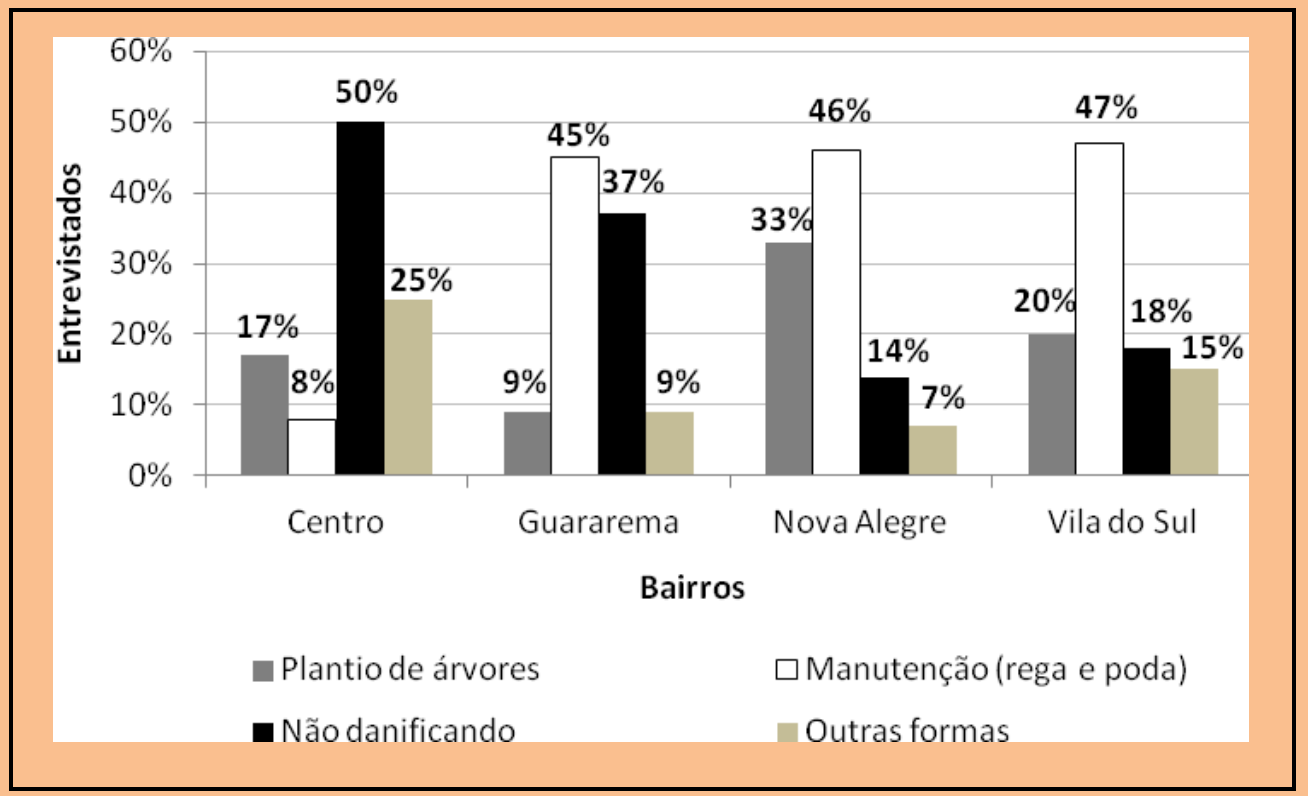

Samira Murelli de Souza et al. 
Pode-se observar que houve bastante variação entre os bairros, nas atividades realizadas pelos entrevistados. Analisando cada bairro separadamente, percebe-se que no Centro do município de Alegre, metade dos entrevistados apontou que colabora com a arborização não danificando as árvores. A outra metade encontra-se dividida pelo plantio de árvores nas ruas, manutenção e outras formas, como controle de formigas, cupins e proteção à árvore por meio de cercas.

No bairro Guararema, 45\% dos entrevistados realizam a manutenção, 37\% colaboram não danificando as árvores, enquanto os demais ajudam com plantios de mudas e por outras formas, sendo a mais destacada dentre elas, o controle de pragas.

No bairro Nova Alegre, a maior parte colabora por meio de manutenção (46\%) das árvores presentes em suas ruas, enquanto 33\% afirma já ter ajudado a partir de plantios de árvores.

Por último, no bairro Vila do Sul, novamente as atividades mais realizadas pelos entrevistados é a manutenção (47\%) e o plantio de árvores (20\%).

Esses resultados demonstram certa contradição nas atitudes dos próprios entrevistados, uma vez que a maioria deles tem conhecimento de quem é a instituição responsável pela arborização, mas que contraditoriamente, afirmam colaborar plantando árvores nas ruas e podando-as sem a permissão e a orientação correta de profissionais especializados e vinculados à prefeitura municipal.
Segundo Castro (2004), colaborar plantando árvores e realizar manutenção e poda pode ser prejudicial, com implantação de espécies inadequadas, ou também com a realização da poda de forma desnecessária e desordenada, podando indivíduos muito jovens e muitas vezes podendo até ocasionar a mutilação da árvore. Além disso, Roppa et al. (2007) cita o dano ocasionado à copa, deixando a árvore exposta as ataque de pragas e doenças pelo estresse fisiológico imposto pela prática, o que frequentemente ocorre em cidades do interior.

Para Brun et al. (2009), outra grave conseqüência é o plantio de espécies com princípios tóxicos em seus tecidos, que oferecem grande risco a crianças e animais, que não sabem discernir o que é comestível do que não é. Além disso, o mesmo autor afirma que as podas drásticas, realizadas rotineiramente, ocasionam nos indivíduo distúrbios nas reservas energéticas e na translocação de nutrientes para as raízes, o que reduz consideravelmente a copa e o sistema radicular, aumentando a propensão ao risco de queda da árvore.

Por último, o presente estudo buscou identificar as opiniões dos entrevistados sobre o que poderia ser feito para melhorar a arborização das ruas nos bairros de Alegre.

Na Figura 10, observa-se então, as opções de melhorias, segundo a percepção ambiental dos entrevistados. 
FIGURA 10. Sugestões apontadas pelos entrevistados para a melhoria da arborização urbana de suas ruas, nos bairros avaliados, do município de Alegre, ES.

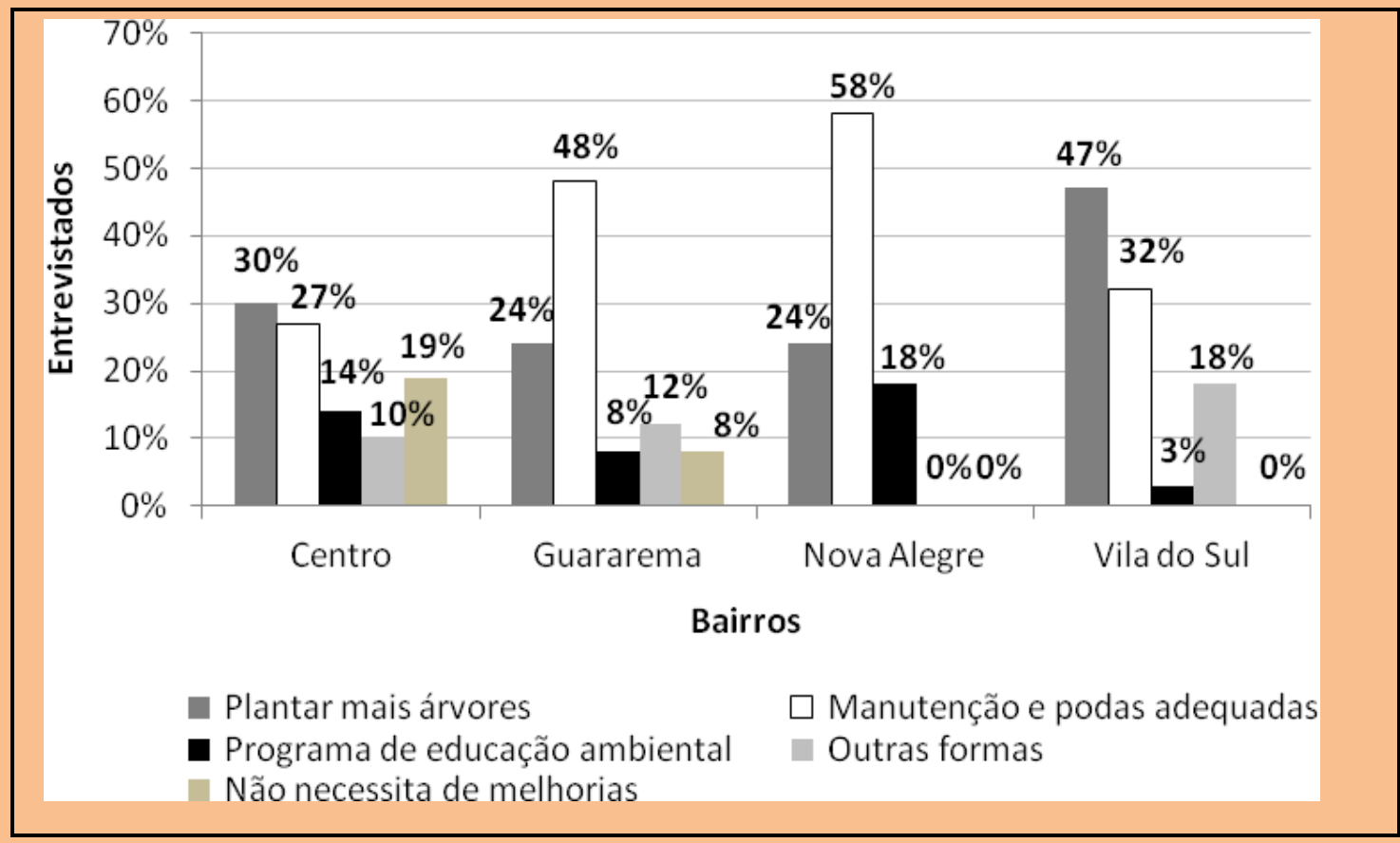

Verifica-se que, em todos os quatro bairros avaliados na cidade de Alegre, as principais melhorias a serem realizadas em prol da arborização das vias públicas, é a realização de manutenção e podas de forma e época correta, plantio de mais árvores nas ruas com escolha das espécies mais adequadas ao local, e a criação de um programa de educação ambiental, com intuito de promover a conscientização da população, sobre a importância da arborização no meio urbano e sua preservação.

De acordo com Pires et al. (2007), a escolha adequada da espécie em função do espaço aéreo disponível para o seu desenvolvimento pleno pode eliminar necessidades de poda, ou restringir as podas, simplesmente, a aspectos de limpeza e aeração para a saúde da árvore e nunca a mudanças na sua conformação natural.

Resultados semelhantes foram identificados no estudo de Rodrigues et al. (2010), em Pires do Rio, Goiás, onde a maioria dos entrevistados afirmou que o plantio de mais árvores é uma das medidas para melhorar a arborização das ruas, seguido da promoção de campanhas de conscientização da população, assim como maior atenção da entidade responsável pela manutenção, incluindo poda correta e periódica.

Em relação àqueles que acham que a arborização de suas ruas não necessita de melhorias, tem-se que no Centro de Alegre, 19\% responderam estar satisfeitos com a configuração e a quantidade de árvores presentes em seu bairro. Na Guararema, apenas $8 \%$ demonstraram satisfação com a arborização. Em contrapartida, nos bairros Nova Alegre e Vila do Sul, nenhum dos entrevistados respondeu que a arborização de seus respectivos bairros encontra-se totalmente adequada.

Pronsato (2005) citado por Brun et al. (2009), ressalta que a implantação de programas de educação ambiental sobre a relevância da arborização urbana poderia levar os moradores a perceber e questionar-se sobre o natural, pois parte 
da população que vive nas cidades só conhece o ambiente construído.

A falta de participação comunitária nos programas de arborização gera sérios prejuízos. Percebe-se nitidamente que o "vandalismo" tornou-se uma das mais notáveis formas de interação entre o homem urbano e a arborização, por isso a educação da população com relação aos efeitos benéficos da arborização é uma forma de reduzir os seus efeitos deletérios (MALAVASI \& MALAVASI, 2001).

\section{CONCLUSÃO}

Diante dos resultados levantados, observa-se que, em geral, a população do município de Alegre, entende a importância da arborização no contexto urbano e seus benefícios à qualidade de vida. Constatou-se que alguns entrevistados, além de possuírem percepção ambiental, têm proposições em relação à gestão ambiental.

Os resultados também mostraram que o sexo, idade e escolaridade influenciaram em algumas das questões abordadas. No sexo feminino notaram-se opiniões mais formuladas e detalhadas, assim como as respostas de entrevistados com maior faixaetária, proveniente da maior vivência e experiência. Entretanto, foi percebido certo grau de dificuldade nos entrevistados com baixo grau de escolaridade, sendo que alguns não conseguiram compreender o significado do próprio termo “arborização”.

É recomendável a criação de programas de orientação técnica e educação ambiental à população de Alegre, no que tange a arborização urbana, a partir de parcerias entre Universidades, Prefeitura Municipal e Companhias privadas. O objetivo deve ser o de proporcionar aos moradores, o acesso às informações, realização de atividades práticas, aquisição de conhecimentos e conscientização sobre a importância da preservação ambiental de seu município.

\section{REFERÊNCIAS BIBLIOGRÁFICAS}

BRUN, F. G. K.; LONGHI, S. J.; BRUN, E. J. Estudo da percepção da população de Vilas do Bairro Camobi, Santa Maria - RS sobre a arborização urbana. Revista de Estudos Ambientais, v.11, n.1, p.6-11. 2009.

IBGE - Instituto Brasileiro de Geografia e Estatística. 2010. Disponível em: < http://www.ibge.gov.br/cidadesat/painel/painel.php?codmun=320020>. Acesso em: Set. 2011.

LOBODA, C. R.; DE ANGELIS, B. L. D.; DE ANGELIS NETO, G.; SILVA, E. S. Avaliação das áreas verdes em espaços públicos no município de Guarapuava, PR. Ambiência. Irati, PR: v. 1, n. 1, p. 141-155, 2005. 
MACHADO, L. M. C. P. A praça da Liberdade na percepção do usuário. Revista Geografia e Ensino, São Carlos, SP: v. 5, n. 1, p. 19-33, 1993.

MALAVASI, U. C.; MALAVASI, M. M. Avaliação da arborização urbana pelos residentes - estudo de caso em Marechal Cândido Rondon, Paraná. Revista Ciência Florestal, Santa Maria, v.11, n.1, p.189-193, 2001.

OLIVEIRA, E. Z. Percepção ambiental x arborização urbana dos usuários da avenida Afonso Pena entre as ruas Calógeras a Ceará em Campo Grande - MS. 2005. Disponível em: <http://www.repams.org.br/downloads/ARTIGO\%20DO\%20MESTRADO.pdf>. Acesso em: Set. 2011.

PIRES, R. K; DIAS, M.B.; BRITO,J. O conflito:arborização x energia elétrica,no bairro vermelha, em Teresina,PI. II Congresso de Pesquisa e Inovação da Rede Norte Nordeste de Educação Tecnológica João Pessoa - PB, 2007.

PIVETTA, K. F. L. SILVA FILHO, D. F. Arborização urbana. Jaboticabal, SP: UNESP, FCAV, FUNEP (Boletim Acadêmico), 69p. 2002.

PREFEITURA MUNICIPAL DE ALEGRE. Características gerais da cidade. Disponível em: <http://www.alegre.es.gov.br/index.php?option=com_content\&view=article\&id=143\&Itemid=96>. Acesso em: Set. 2011a.

PREFEITURA MUNICIPAL DE ALEGRE. Serviço de poda de árvores em Alegre. Disponível em: $<$ http://www.alegre.es.gov.br/index.php?option=com_k2\&view=item\&id=971:serviço-de-poda-de-árvores-emalegre-é-realizado-por-equipe-especializada\&Itemid=144>. Acesso em Set. 2011b.

QUADROS, L. S.; FREI, F. Percepção ambiental dos residentes da cidade de Assis - SP com relação à arborização viária da Avenida Rui Barbosa. Revista da Sociedade Brasileira de Arborização Urbana. Piracicaba-SP, v.4, n.2, p.16-34, 2009.

RIBEIRO, F.A.B.S. Arborização urbana em Uberlândia: percepção da população. Revista da Católica, v. 1, n. 2, p. 224-237, 2009.

RODRIGUES, T. D.; MALAFAIA, G.; QUEIROZ, S. E. E.; RODRIGUES, A. S. L. Percepção sobre arborização urbana de moradores em três áreas de Pires do Rio - Goiás. Revista de Estudos Ambientais, v. 12, n. 2, p.47-61. 2010.

ROPPA, C.; FALKENBERG, J. R.; STANGERLIN, D. M.; BRUN, F. G. K.; BRUN, E. J.; LONGHI, S. J.; Diagnóstico da percepção dos moradores sobre a arborização urbana na Vila Estação Colônia - Bairro Camobi, Santa Maria - RS. Revista da Sociedade Brasileira de Arborização Urbana, v. 2, n. 2, 2007.

SANTOS, N. R. Z. dos; TEIXEIRA, I. F. Arborização de Vias Públicas: Ambiente X Vegetação. Santa Cruz do Sul: Instituição Souza Cruz, 135 p. 2001. 
SILVA, L. F.; FILIK, A. V.; LIMA, A. M. L. P.; SILVA FILHO, D. F. Participação comunitária no planejamento viário de alguns bairros da cidade de Americana - SP. Revista da Sociedade Brasileira de Arborização Urbana. Piracicaba, SP: v. 2, n. 3, p. 47-62. 2007.

STRINGHETA, A. C. O. Arborização Urbana no Brasil. Ação Ambiental, Viçosa, MG, v. 8, n. 33, p. 9-11. 2005.

TEIXEIRA I. F. Análise Qualitativa da Arborização de Ruas do Conjunto Habitacional Tancredo Neves, Santa Maria - RS. Ciência Florestal, v. 9, n. 2, p. 9-21, 1999.

ZINKOSKI, A.E.; LOBODA, C.R. 2005. Arborização: uma percepção do espaço urbano na área central de Guarapuava, PR. In: VII COLOQUIO INTERNACIONAL DE GEOCRÍTICA. Anais... Santiago de Chile: Instituto de Geografia - Pontificia Universidade Católica de Chile, 2005. 